\title{
Health Promotion Program (JUMSIH); To Enhance Children's Clean and Healthy Living Knowledge
}

\author{
Yufiarti $^{1}$ \\ Universitas Negeri Jakarta, Indonesia \\ Edwita $^{2}$ \\ Universitas Negeri Jakarta, Indonesia \\ Suharti ${ }^{3}$ \\ Universitas Negeri Jakarta, Indonesia
}

DOI: https://doi.org/10.21009/JPUD.132.10

Accepted: August 15 $5^{\text {th }} 2019$. Approved: September $4^{\text {th }} 2019$. Published: $30^{\text {th }}$ November 2019

\begin{abstract}
Knowledge about clean and healthy life in children needs to be given early to shape behavior in everyday life. Knowledge about healthy living can be provided at school through various learning programs. This study aims to find the effectiveness of health promotion programs (JUM$\mathrm{SIH})$ to increase children's knowledge about clean and healthy living. The research method is a preexperimental one-shot case study design. The respondents of this study were 68 students aged 7-8 years. The results showed that the JUMSIH program can help children have knowledge about healthy living. Based on data analysis, $\mathrm{n}=15$ generally obtained scores above 2.6. It was concluded that healthy living skills are often performed by students such as hand washing, bathing, and toothbrush behavior which are basic skills for children to be able to live healthy lives. Suggestions for further research which is the development of various programs to increase awareness of clean and healthy living from an early age.
\end{abstract}

Keywords: Clean and healthy life Knowledge, Early Childhood, Health Promotion Program (JUM$\mathrm{SIH})$

\footnotetext{
${ }^{1}$ Corresponding Author:

Email:yufiarti@unj.ac.id
} 


\section{INTRODUCTION}

Education and care services have an obligation to ensure that everyone is provided with a healthy and safe environment for playing and working. All educators / staff are given full information about their responsibilities to implement and comply with health service policies and procedures. All children have the right to develop their full potential in an environment that provides their health, safety and well-being. Effective hygiene strategies and practices help services to protect everyone from and minimize the potential risk of communicable diseases. Experiences that promote awareness of basic hygiene help children become competent and independent and develop valuable life skills (Considerations \& Framework, 2010).

To be clean and healthy, ECE needs to identify what makes their services safe and sound. Educators must think about the environmental safety provided by the service, along with group and individual health and the wider environment outside (children, staff, parents, caregivers, and families) All ECEs must respond to health or safety problems or problems when they arise. Children's educational institutions can improve and protect health and safety by identifying, and placing protective measures around, problems that might or might cause problems before they occur (Midcentraldhb, 2014).

Several studies were conducted to look at intervention programs in early childhood regarding hygiene and health. Conti, Heckman, \& Pinto, (2016) research discusses the long-term impact on health and healthy behavior of two early childhood interventions (1) Perry's Preschool Project (PPP) and (2) Carolina Abecedarian Project (ABC). These results indicate the potential for early life interventions to improve health. Duxbury, Bradshaw, Khamanga, Tandlich, \& Srinivas, (2019) conducts research to increase individual environmental health awareness through computer-based training; education poster; interactive board game; and the take-out information leaflet is used for student-centered health improvement accumulation.

Most health behaviors developed during child health promotion must begin early. Kindergarten has proven ideal for such interventions. Interventions and materials were developed using the Bartholomew Intervention Mapping approach considering Bandura's social-cognitive theory and Bronfenbrenner's ecological framework for human development. The results from the Kobel et al., (2017) study provide a better understanding of health behavior in early childhood and to identify strategies for effective health promotion.

In the process of internalizing awareness to maintain personal and environmental health, there needs to be an effort to get used to maintaining health. Habitual activities safeguarding health will emerge when knowledge about clean and healthy life is already possessed by individuals and the community. So, with the knowledge possessed, it is expected that individuals and the community will gradually free up Clean and Healthy Behavior. Clean and Healthy Life Behavior is a reflection of family life patterns that always pay attention and maintain the health of all family members (Proverawati, 2012). Every family member and community consciously behaves in a way that reflects a clean and healthy life so that they can help themselves in their activities (Julianti, Nasirun, \& Wembrayarli, 2018). Therefore, real efforts from various parties are needed for the realization of clean and healthy living habits that are entrenched in all elements, including the family, school and community environment. covering the family, school and community environment.

Additional factors can influence the success of health promotion interventions in children. Adverse socioeconomic status can be associated with family tensions and emotional problems in 
children, which can lead to unhealthy habits. Consequently, underserved children tend to be very worried about high disease rates. Furthermore, children from low socioeconomic status are generally less affordable through lifestyle interventions, and socioeconomic status can influence the efficacy of health improvement programs. Nevertheless, some intervention studies target both lower income and richer populations to examine the feasibility of reducing or eliminating disparity.

Schools become an important place in instilling clean and healthy behavior from an early age. Healthy behavior is associated with efforts to preserve, maintain and improve their health. For example, This behavior can be improved through the role playing method of children who can practice healthy behavior directly, so that it will impress deeply for children (WIjayanti, 2017). Based on the importance of knowledge in early childhood to maintain hygiene and health, this study aims to find the effectiveness of health promotion programs (JUMSIH) to improve children's knowledge about clean and healthy living.

\section{THEORITICAL STUDY}

\subsection{Health Promotion Program (JUMSIH)}

Humans as whole beings consist of physical and spiritual elements. In carrying out daily activities, humans must be healthy, physically healthy and spiritually healthy. Spiritual health alone is not enough, and vice versa. Therefore, human health is needed in life. Humans should be grateful for the healthy favors that God has given. With health, human productivity can increase along with the physical strength it has. With health, humans can work and do activities to support their lives. Maintaining health is an individual task and a joint task. Health is an individual duty if health is related to personal health. In addition, health will be a joint task of all members of the community when it relates to environmental health. Therefore, each person, family member, community and all parties need to take care of their health, both personal health and environmental health (Proverawati, 2012).

Historically, health education in schools has been discussed in class using a topic approach (i.e. physical activity, healthy eating and mental health) while HPS offers a more holistic 'whole school' approach that complements the class curriculum. For example, teaching and involving students in gardening schools, building inclusive school food programs or incorporating physical activity into the classroom curriculum (Mcisaac, Sim, Penney, \& Kirk, 2012). This approach shifts the focus from individual student behavior to building a school environment that improves. As a result of shifting in emphasis, HPS requires new ways of thinking about health and the role of schools (WHO, 2016)

Teachers are usually asked to provide data on early childhood education experiences in the year before starting school, as well as five important domains of child development upon entering school: physical health and well-being, social competence, emotional maturity, language and cognitive skills, and communication skills and general knowledge. Goldfeld et al., (2016)'s research results show that engagement with preschool programs in Australia can present a reasonable, fair and modifiable approach to improve children's health knowledge.

The school-promoting health aims to make schools a healthy place through a holistic approach that promotes a 'school ethos' that supports and emphasizes physical, social, and emotional improvements in welfare and educational outcomes. The development of a healthy child in turn is 
associated with better health outcomes later in life (Mikkonen, J., Raphael, 2010). Schools offer the ideal set of health promotion interventions because most children spend a large part of their day there. Many school-based health promotion interventions have traditionally focused on changing individual behavior.

The School of Health Promotion (school-promoting health, also known as the Coordinated School of Health or Comprehensive School of Health) is a multicomponent intervention that emphasizes improving educational and physical, social, and emotional outcomes. Internationally, school-promoting health has been found to have a small, but positive effect on health behavior and several aspects of social welfare (Langford, R., Bonell, C.P., Jones, 2014). However, several studies have shown the effectiveness of school-promoting health in improving children's health behaviors (Fung, C., Kuhle, S., Lu, C., 2012).

This framework was adapted from recommendations by the World Health Organization and focused on health coaching and learning, involving all school partners (staff, students, parents, and the community), providing an environment that supports health, and implementing healthy policies and practices (WHO, 2016). School-promoting health adaptation is an important feature because it ensures flexibility for a variety of school contexts across the country (Keshavarz, N., Nutbeam, D., Rowling, L., Khavarpour, 2010; Veugelers \& Schwartz, 2010).

School ethos reflects a variety of physical and psychosocial structures that can shape the school environment and, in changing, affect the health and well-being of students. Although school ethos is understood as an important component of school-promoting health (Samdal, O., Rowling, 2011). The school-promoting health initiative is based on the needs and assets of each school community. The school board adopted the school-promoting health, setting the stage for natural population health experiments (Hawe, P., Potvin, 2009).

The school has a mandate to provide education. This may include health education delivered through fields of study, such as science, or through special health courses and physical education. Students can learn effectively and can demonstrate learning facts obtained. However, encouragement for students to change their behavior requires a more comprehensive approach that involves parents, the community and stakeholders, and includes supporting policies, programs and environments.

This article provides a review of school-promoting health specifically for the promotion of healthy eating and active living. It further provides some general understanding of the wider implementation and benefits of school-promoting health for students and schools, as well as suggestions for future research to increase the evidence base for public health benefits from school-promoting health (Veugelers \& Schwartz, 2010). Diversity within the school environment can play a relevant role in the successful implementation of school and policy-based interventions. Schools vary greatly in terms of content, community involvement, financial support, and delivery of interventions, which can influence the efficacy of childhood education programs. In addition, the characteristics of teachers may be important considering that they are one of the pillars in the development of children and play an important role for the successful implementation of school-based health promotion programs (Fernandez-Jimenez, Al-Kazaz, Jaslow, Carvajal, \& Fuster, 2018).

Through education, school may play a major role in promoting long-lasting healthy habits in children, because these people spend most of their day there. Evidence shows that when healthy habits are adopted early in life, they are more likely to be maintained in adulthood; therefore, school- 
based interventions are considered a promising approach to shape healthy behavior from an early age.

In addition, this intervention can benefit executive functioning and achievement of public schools in children. Many school-based interventions studies have been carried out in preschool settings; However, little has been tested in randomized trials. Most studies are focused primarily on preventing weight gain by only discussing 1 lifestyle component, such as diet or physical activity, with small interventions as a whole effect size. Similar problems and overall modest effect sizes have been reported in a meta-analysis conducted in older children.

\subsection{Children's Clean and Healthy Living}

Clean and healthy living behavior influenced by many factors such as habits at home, community environment, and in the school environment. There needs to be a continuous habituation effort so that clean and healthy living behavior in children can be done consciously without the need to be repressive to sensitize the community, such as fines when littering and so on. The habit that is done every day has not been able to increase children's awareness (Julianti et al., 2018). To raise awareness, efforts should also be made to provide knowledge about clean and healthy living. Habituation is one of the ways that can be carried out to carry out clean and healthy living behaviors.

The habit of maintaining personal hygiene can be done with activities such as washing hands before eating, brushing teeth, cleansing after urinating, bathing and so on. The habit of maintaining environmental cleanliness can be done through activities such as throwing trash in its place, limiting the use of plastic, using clean water, and so on. The habit of clean life behavior in children, especially in early childhood can be assisted with visual aids such as pictures and infrastructure. Props in the form of pictures such as sticking pictures of how to wash hands properly and properly in the place of washing hands, sticking pictures throwing trash in their place in a place that is easily visible to children when children eat lunch, and so on.

Facilities and infrastructure that can help children get into the habit of living a clean lifestyle such as a place to wash hands that are about the size of a child's body, provide a trash bin that is easily accessible to children when going to throw out trash and so on. Efforts to facilitate clean and healthy living habits in schools can be planned by the school and parents. Can also do cooperation and involves parents who provide healthy food every month. The teacher can design a variety of other creative activities to familiarize clean and healthy behavior in children. Also, efforts that can be made by teachers in schools that have a significant effect on children are exemplary. The teacher can give for example, throwing trash in its place, washing hands before eating, and so on.

Children's behavior can be shaped through experience and interaction with their environment. The behavior is manifested from the results of the knowledge gained, the experiences carried out and interactions with the environment, both the family environment, the school environment, and the community environment. Behavior cannot just appear without a prior knowledge base. Therefore, providing knowledge about the concept of a clean and healthy life is very important to do.

Various factors can affect changes in a child's attitude, namely internal factors and external factors. Internal factors are innate in the form of a child's ability to respond to external stimuli. Besides the internal factors that influence behavior are perception, motivation, and emotion. Perception is observation which is a combination of vision, hearing, smell, and experience. A similar object can be perceived differently by several people. Motivation is the drive to act to fulfill a 
need while emotions are related to an individual's personality. The external factors are factors that exist outside of a child, for example, examples of clean and healthy living behavior that is seen every day in the form of throwing garbage in its place.

Clean and healthy life behavior closely related to individual behavior in the community. Often encountered, the cleanliness behavior of individuals is already good, but because the community environment does not support so slowly the behavior that has been formed gradually eroded. Community behavior has not yet led to healthy behavior, especially in relation to environmental health and personal hygiene (Kasnodihardjo, 2010). Community behavior is less positive because it has not been motivated based on awareness of the importance of healthy values. The results of this study indicate that socialization and exemplary about PHBS still need to be carried out, for this reason a change agent is needed. The school environment as an educational environment is expected to be an agent of change in the community. So that the school environment can prepare students to have adequate character to conduct clean and healthy life behaviors for themselves and the community.

Changes in clean and healthy living behavior can be made by referring to the assumption that the individual as part of the community is the subject of health services. In this case, each individual in the community needs to be invited to participate in identifying and discussing health problems as well as actively seeking alternative solutions to problems. However, with a diverse educational and socio-economic background, this understanding effort is less effective. Efforts to instill awareness of clean and healthy living behaviors in the community are effectively carried out among highly educated people and upper-middle economic levels.

Health is not only the absence of disease, but also the conditions that function mentally, socially, physically, and spiritually. Health is an ever evolving and complex continuum which is significantly influenced by an individual's lifestyle habits. Adopt health behavior style promotion life, is defined as 'all the actions and beliefs of individuals which are upheld to stay healthy and prevent themselves from illness', can bring about long-desired advertisements and changes in one's life. Healthy behavior covers a variety of domains, such as physical practice, health responsibilities, spiritual growth, nutrition, stress management, and interpersonal relationships.

Health is the right of every person, not just the dominance of individuals or certain communities. Clean and healthy life behavior is a step that must be done to achieve optimal health for everyone. Healthy conditions do not necessarily occur but must always be sought from the unhealthy to a healthy life and create a healthy environment. This effort must start from instilling a healthy mindset to the community that must be started and cultivated by yourself. Efforts to optimize public health aim to realize the degree of public health as well as possible so that it can become the main capital for the development of productive and superior human resources. To familiarize clean and healthy living behaviors, a shared commitment is needed to support one another in improving the health status of the community, especially families, so that healthy development can be achieved optimally.

WHO states health is one of the rights of individuals to be able to carry out all forms of activities or daily routines. In order to live a healthy life, everyone must be able to have good behavior, which is a Clean and Healthy Lifestyle. Clean and Healthy Lifestyle is a strategy used to create independence in creating and achieving health and is a behavior that is implemented based on awareness that is the result of learning that can make individuals or family members can improve their health in the field of public health. 
Clean and Healthy Lifestyle one of the essences and human rights to maintain its survival. This is consistent with what is covered by the WHO constitution which states that a high degree of health is a fundamental right for individuals. This right applies to all people regardless of origin, religion, race, politics and economic level. This high degree of health can be obtained if everyone has behaviors that pay attention to health.

The concept of behavior developed by Becker based on the concept of healthy behavior Bloom. Becker explained that healthy behavior is divided into three domains, namely health knowledge, attitude to respond to health actions (health attitude) and practice or health action (health practice). This domain is useful to find out how much the level of healthy behavior of each individual. Healthy behavior divides into the first three parts, knowledge about health, that is, what is known by individuals about how to improve and maintain health. Second, the attitude to respond to health actions, namely the individual's assessment of matters relating to how to maintain health. Third, practice or health action which is a direct action consisting of all activities to obtain a healthy life.

This healthy behavior is a behavior that is used to maintain, improve health, avoid or prevent disease, protect themselves from various diseases, and participate in improving the quality of health. The improvement program is not only limited to a healthy environment and health services, but also pay attention to behavioral factors, this is because behavioral factors can be a factor in the occurrence of various diseases, both infectious and non-communicable diseases (Marlina, 2011).

The quality of each human resource is determined by two interrelated and related factors. These factors consist of education and health. Health is the main requirement in obtaining the success of educational efforts, while education is one of the factors for achieving high health status of each individual (Maryunani, 2013). Clean and Healthy Lifestyle in the school environment has eight indicators, namely washing hands with running water and using soap, consuming healthy snacks in the school canteen, using clean and healthy toilet facilities, carrying out regular exercise, eradicating mosquito larvae at school, not smoking in the school environment, curating weight and height, as well as throwing away trash in the space provided. These eight indicators must be done well to create healthy behavior in the school environment.

Schools are educational institutions that are targeted by PHBS, so that the application of these behaviors is better. This is because there is a lot of data that shows that most of the diseases that are often suffered by school-age children (ages 6-10) are in fact related to PHBS. In addition, the lack of implementation of Clean and Healthy Lifestyle in the school environment can cause other impacts, namely the lack of comfortable learning atmosphere due to dirty classroom environment, decreased student achievement and enthusiasm for learning, and can make the school's image worse. Therefore, it is very necessary to provide an understanding of PHBS values early on in school (Proverawati, 2012).

The promotion of clean and healthy life behavior in schools can be given to three PHBS target groups, the primary target, secondary target, and tertiary target. The primary target in the development of clean and healthy life behavior in schools is elementary students, where they are expected to be able to know and implement clean and healthy life behavior. Secondary targets are people who influence the primary goal in deciding to implement clean and healthy life behavior. At clean and healthy life behavior in schools, the secondary target is the teacher, where a teacher is a role model of the students. Tertiary targets are people who function to make formal decisions, such as school committees, village heads, education offices, and so on. They can provide support 
in determining policies, funding in the process of Guiding clean and healthy life behavior to be given to school students.

RI Law No.36 year 2009 chapter VI article 79 Paragraph, on Health Efforts explains that efforts to foster health in the school environment are held with the aim of improving and developing healthier life skills by students. This ability must be applied in a healthy living environment, so that school-age children can learn, grow, develop and obtain the highest health status in order to become a qualified human resource. According to WHO, as many as 100,000 Indonesian children die from diarrheal disease each year, while data from the Ministry of Health show that of 1,000 residents, there are 300 people who suffer from diarrhea throughout the year.

Indonesia's Health Profile for 2009 presents data that, there are as many as $64.41 \%$ of the facilities that have been fostered by the environment to implement a clean and healthy life. The facilities consist of educational institutions as much as $67.52 \%$, workplaces as much as $59.15 \%$, and other environments as much as $62.26 \%$. Clean and healthy life in the education setting, workplace environment, and health facility environment has not run as desired, therefore a comprehensive, cross-program and cross-sector approach is needed, and extraordinary resource mobilization at all levels government administration (Syukriyah, 2011).

The National Basic Health Research report states that health is influenced by behaviors that uphold hygiene conditions. Due to the lack of attention to cleanliness, there are still many diseases that arise such as diarrhea, helminthiasis, filariasis, dengue fever, and vomiting. Hygiene problems that are still mostly experienced by elementary school students, namely problems with teeth as much as $86 \%$, can't cut nails as much as $53 \%$, can't brush teeth as much as $42 \%$ and don't wash their hands before eating as much as $8 \%$. While the diseases that are mostly suffered by elementary school students are intestinal worms of $60-80 \%$, and dental caries as much as $74.4 \%$. Therefore, to overcome this problem, it is necessary to have comprehensive efforts from various sectors.

The school environment as an educational environment is a very strategic environment to provide knowledge and instill habituation about clean and healthy living. Learners will more easily follow the rules that apply in schools. So that schools can make various activities that are integrated with learning activities programs. The activity program can be a general program that is applied to all students in the school or a class program specifically created by the class teacher together with his students. General programs that can be carried out in schools can be in the form of health promotion programs and carried out simultaneously by all students. Health promotion activities have been carried out by SD Lab school, Jakarta State University, in the form of Clean Friday activities, commonly abbreviated as JUMSIH.

JUMSIH activities are carried out every Friday and involve all students in the school. The children are divided into groups and given tasks by the division of labor, the division of labor includes sweeping and mopping the class floor, cleaning the classroom glass, sweeping the yard, cleaning the fishpond, cleaning the bathroom, and so on. The division of work takes turns divided into different groups so that each child can feel the different tasks in each JUMSIH activity.

In the JUMSIH activity, the children are actively involved and work together in groups. JUMSIH is a health promotion activity designed by the school and involves all school residents. The objective of JUMSIH is to familiarize clean and healthy living behavior in the school environment and is expected to form a clean and healthy character of each student. 


\section{METHODS}

\subsection{Partisipant}

This research was conducted in elementary schools in Jakarta. The sampling technique uses purposive sampling technique that is the sampling technique with specific considerations and objectives (Creswell, 2012). In this study aims to determine the clean and healthy life promotion program conducted at school. Schools that fulfill this research objective are SD LabSchool, Jakarta State University. The sample of this study were 68 students including all grade 3 students at SD Labschool, Universitas Negeri Jakarta.

\subsection{Research Design}

This study uses a pre-experimental design with one-shot case study. In research that uses this design, it is only done in one group. After treatment, post-test is immediately carried out on the sample (Gall, Gall, \& Borg, 2007). The design of this study uses a treatment in the form of a Jumsih program which is a clean and healthy life promotion program implemented at SD LabSchool. The research design is illustrated in the following table 1 below:

Table 1. Research Design Experiment

\begin{tabular}{cc}
\hline $\mathbf{X}$ & $\mathbf{O}$ \\
\hline Treatment of JUMSIH & Posttest of healthy and Clean Knowledge \\
\hline
\end{tabular}

\subsection{Instrument}

This research instrument has passed the instrument validity test and expert test related to knowledge about clean and healthy life for early childhood. This instrument is used to be an indicator of test questions given to respondents (see table 2).

Table 2. Clean and Healthy Living Knowledge

\begin{tabular}{cl}
\hline NO & \multicolumn{1}{c}{ PERTANYAAN } \\
\hline 1 & Benefits of washing hands \\
2 & Diseases arising from not washing hands \\
3 & When to wash your hands \\
5 & Dangerous snack at random \\
6 & What you need to keep in mind when buying food \\
7 & Why urinate and defecate must be in the toilet \\
8 & Here are the main objectives of sport \\
9 & Mosquito bites can cause diseases, among others \\
10 & How to eradicate mosquito larvae \\
11 & Weighing your weight and measuring height is done regularly every time \\
12 & The benefits of weighing and measuring height are carried out regularly, among \\
& others \\
13 & Weight and height results \\
15 & Garbage is a nest \\
16 & Types of waste \\
17 & The following is an example of dry waste \\
18 & How to manage rubbish bins, among others \\
19 & How to maintain environmental health from rubbish \\
\hline
\end{tabular}




\subsection{Procedures}

The research was carried out during August 2019. Research procedures include the preparation, implementation and evaluation stages. In the preparation phase, the researcher visits the school where the research is carried out. This preparation stage includes, (1) determining the research sample; (2) observation of research sites; (3) initial observation of the research sample; (4) Teacher interviews about the JUMSIH program; and (5) Designing a post-test schedule.

At the research implementation stage, they included (1) observations of the implementation of the JUMSIH program 3 times Friday; (2) Interview of respondents during the implementation of JUMSIH; and (3) Post-test implementation to find out students' knowledge about clean and healthy living knowledge. At the evaluation stage, the researcher conducts a final review of the activities of the sample and a final interview with the teacher about student knowledge.

Implementation refers to material learning plans to find out students' knowledge about clean and healthy living. The implementation consists of three stages, namely introduction, core activities, and closing. This activity consists of exploration, elaboration, and confirmation. Observations made by researchers to find and obtain data about everything that happens and observe or record changes in student learning outcomes during the learning process takes place as a benchmark for the success of the JUMSIH program towards students' knowledge about clean and healthy living. In this research procedure, the researcher collaborates with the classroom teacher.

\subsection{Data Analysis}

Data analysis in the study used score measurements obtained by the sample at the time of the post-test. The sample conducts tests to measure knowledge about clean and healthy living. The questions given contained material that was diseased with knowledge of clean and healthy living. The value obtained by students is calculated based on the provisions, if correct get a score of 1 , and if one gets a value of 0 . The score is added up and becomes the final score obtained by students.

\section{RESULTS AND DISCUSSION}

The results of this study indicate the results of tests on clean and healthy living knowledge, the following data are obtained: as many as 5 students (7.4\%) who answered correctly one clean living knowledge problem, 8 students (11.8)\% who answered two to three questions, 16 students $(23.5 \%)$ who answered correctly 4 to 5 questions, as many as 8 students (11.8)\% who answered correctly 6 to 7 questions, as many as 13 students (19)\% who answered correctly 8 to 9 questions, there are 7 students (10.3)\% who answered correctly 10 to 11 questions, and 11 students (16.2)\% who answered correctly 12 to 13 questions. Briefly can be seen in the table and histogram below. 


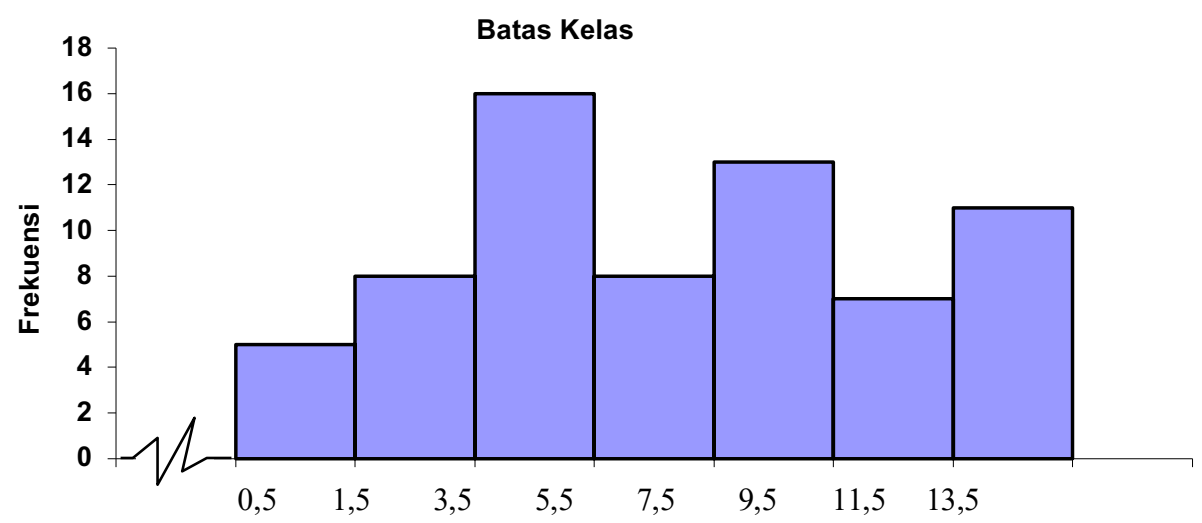

Figure 1. The Results of Tests on Clean and Healthy Living Knowledge

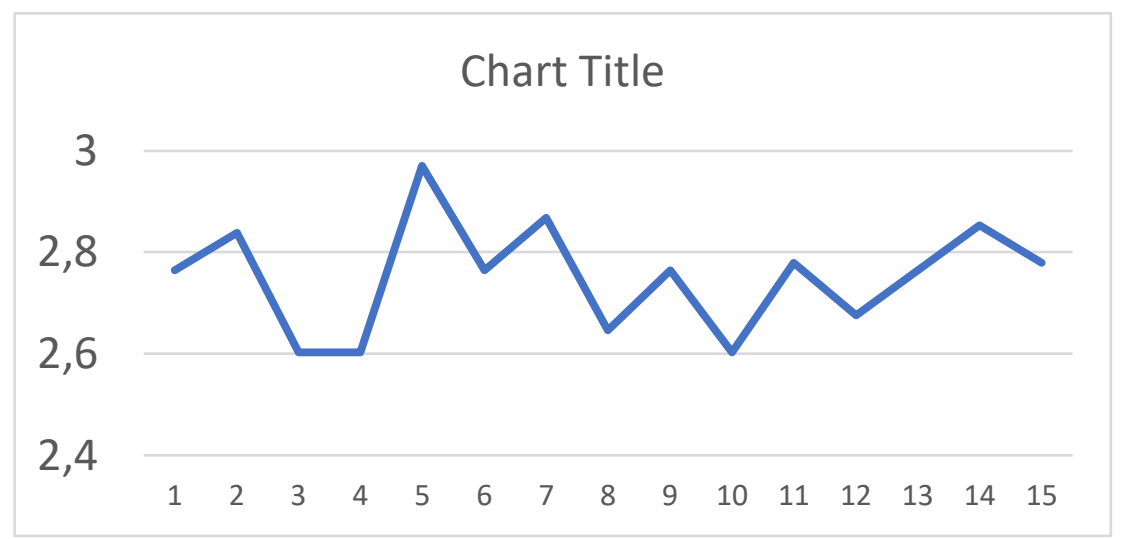

Figure 2. The Histogram Results of Tests on Clean and Healthy Living Knowledge

Based on the histogram above, it can be concluded that students' healthy living skills can be categorized as good. Based on statements which amounted to 15 generally obtained a score of 2.6 and above. It is concluded that healthy living skills are carried out frequently by students. The behavior of washing hands, bathing, toothbrushes which are basic skills for children to be able to live a healthy life have been done by students.

The JUMSIH program as a clean and healthy life promotion program carried out at Lab-School, Jakarta State University, influences students' knowledge about clean and healthy living. The JUMSIH program has proven effective in helping students understand the concepts of clean and healthy living. Like previous research, there is effectiveness through the intervention of health promotion programs in schools in fostering healthy behavior in terms of improvement in healthy eating and active living (McIsaac et al., 2017). School can change the environment and students present reported an increase in fruit and vegetable consumption along with a decrease in energy intake, were more physically active, and showed less obesity compared to students elsewhere.

Schools that have a clean and healthy life promotion program will greatly assist students in gaining knowledge specifically about understanding and behavior about clean and healthy living. The school provides an excellent opportunity to enable students to acquire knowledge and skills and increase the level of activity there is early childhood because children and adolescents should ideally spend significant time in their young lives there and educational efforts can be carried out regularly and continuously. There is plenty of evidence to support the effectiveness of schoolbased health care which is done with good promotional interventions to increase physical activity 
among students. The school environment has a significant impact on sustainable healthy behavior, a key factor in the success of the School of Health Promotion.

The multidimensional approach does not only focus on curriculum-based interventions but also includes policy-based strategies, environmental change, community and parent participation, supplementary school food programs etc. in order to provide opportunities to increase physical activity in a structured and unstructured way (WHO, 2016). Schools can change students' lifestyles that are continually conveying knowledge and skills, as well as influencing values and attitudes.

From this research, it was found that the JUMSIH program could encourage students to cooperate. Because in the implementation of JUMSIH, students collaborate. For example, some children are in charge of sweeping the floor, some sweep the yard, clean the bathroom, clean the pool, and so on. In cooperative learning, the teacher is considered to only create a teaching and learning environment and process. Thus, the teacher must design activities that create learning environments that facilitate students to work together (Akçay, 2016; Manning, M. L., \& Lucking, 1991).

Also, the JUMSIH program can train children to be responsible for their work. Children who have the task of sweeping the floor must be responsible for sweeping and making the classroom clean. Through the JUMSIH program, students enjoy and feel happy because students assume that the implementation of JUMSIH is like refreshing from daily routine activities in class. This is very good for the development and learning process of children and will provide space for children to express themselves through fun activities. JUMSIH program is also an activity that can train children to move their bodies through movement activities such as sweeping, mopping, and so on.

Children's knowledge about clean living can be obtained through family education at home. Parental involvement in providing knowledge about clean and healthy living can make children understand about the concept. The involvement of fathers is very influential to increase children's understanding of the concept of healthy living (Allport et al., 2018). However, schools also have a very important role to provide students with a habit of living a clean life through health promotion programs, for example the JUMSIH program implemented at SD Lab-School, State University of Jakarta.

Health programs in schools that need to be introduced include a variety of things, one of which is about children's sleeping knowledge as a part that is inseparable from clean and healthy living behavior. One of the materials for a good sleeping health program and other intervention for children is the responsibility of parents and teachers (Bonuck, Schwartz, \& Schechter, 2016; McClure, Tarr, Thompson, \& Eckhoff, 2017). The JUMSIH program only focuses on self-promotion programs and the school environment in the form of carrying out activities to clean up the school environment so as to create a clean school environment and children in the school grow healthy.

\section{CONCLUSION}

The results of the study concluded that the JUMSIH program as a school health promotion program which is routinely carried out every Friday effectively to increase students' knowledge about healthy living. This was known from the results of tests conducted in this study. JUMSIH activities that are carried out through hands-on practice make students know about healthy living. Also, students can apply hygiene activities in their daily lives. So hopefully the JUMSIH program can make students have a clean and healthy life behavior. The implication of this research is to 
provide direction for schools to make various health promotion programs for children. With variations in health programs, children are expected to understand more about personal hygiene and health and their environment.

\section{REFERENCES}

Akçay, N. O. (2016). Implementation of Cooperative Learning Model in Preschool. Journal of Education and Learning, 5(3), 83-93. https://doi.org/10.5539/jel.v5n3p83

Allport, B. S., Johnson, S., Aqil, A., Labrique, A. B., Nelson, T., KC, A., ... Marcell, A. V. (2018). Promoting Father Involvement for Child and Family Health. Academic Pediatrics, 18(7), 746-753. https://doi.org/10.1016/j.acap.2018.03.011

Bonuck, K. A., Schwartz, B., \& Schechter, C. (2016). Sleep health literacy in head start families and staff: Exploratory study of knowledge, motivation, and competencies to promote healthy sleep. Sleep Health, 2(1), 19-24. https://doi.org/10.1016/j.sleh.2015.12.002

Considerations, P., \& Framework, N. Q. (2010). Health, Hygiene and Infection Control Strategies for Policy Implementation : 2010(Vic).

Conti, G., Heckman, J. J., \& Pinto, R. (2016). The Effects of Two Influential Early Childhood Interventions on Health and Healthy Behaviour. Economic Journal, 126(596), F28-F65. https://doi.org/10.1111/ecoj.12420

Creswell, J. W. (2012). Educational Research Planning, Conducting, and Evaluating Quantitative and Qualitative Research (4th ed.; P. A. Smith, Ed.). Boston: Pearson.

Duxbury, T., Bradshaw, K., Khamanga, S., Tandlich, R., \& Srinivas, S. (2019). Environmental health promotion at a National Science Festival: An experiential-education based approach. Applied Environmental Education and Communication, 0(0), 1-16. https://doi.org/10.1080/1533015X.2019.1567406

Fernandez-Jimenez, R., Al-Kazaz, M., Jaslow, R., Carvajal, I., \& Fuster, V. (2018). Children Present a Window of Opportunity for Promoting Health: JACC Review Topic of the Week. Journal of the American College of Cardiology, 72(25), 3310-3319. https://doi.org/10.1016/j.jacc.2018.10.031

Fung, C., Kuhle, S., Lu, C., et al. (2012). From "best practice" to "next practice": the effectiveness of school-based health promotion in improving healthy eating and physical activity and preventing childhood obesity. Int. J. Behav. Nutr. Phys. Act., 9, 27.

Gall, M. D., Gall, J. P., \& Borg, W. R. (2007). Educational Research: An Introduction (4th ed.). New York: Longman Inc.

Goldfeld, S., O’Connor, E., O’Connor, M., Sayers, M., Moore, T., Kvalsvig, A., \& Brinkman, S. (2016). The role of preschool in promoting children's healthy development: Evidence from an Australian population cohort. Early Childhood Research Quarterly, 35, 40-48. https://doi.org/10.1016/j.ecresq.2015.11.001

Hawe, P., Potvin, L. (2009). What is population health intervention research. Can. J. Public Health, 100 (Suppl I8-14). 
Julianti, R., Nasirun, M., \& Wembrayarli. (2018). Pelaksanaan Perilaku Hidup Bersih dan Sehat (PHBS) di Lingkungan Sekolah. Jurnal Ilmiah Potensia, 3(1), 11-17.

Kasnodihardjo, K. (2010). Metode pelembagaan perilaku hidup sehat kaitannya dengan kesehatan lingkungan dan hygiene perorangan pada keluarga di Subang Jabar.

Keshavarz, N., Nutbeam, D., Rowling, L., Khavarpour, F. (2010). Schools as social complex adaptive systems: a new way to understand the challenges of introducing the health promoting schools concept. Soc. Sci. Med., (70), 1467-1474.

Kobel, S., Wartha, O., Wirt, T., Dreyhaupt, J., Lämmle, C., Friedemann, E. M., ... Steinacker, J. M. (2017). Design, implementation, and study protocol of a kindergarten-based health promotion intervention. BioMed Research International, 2017. https://doi.org/10.1155/2017/4347675

Langford, R., Bonell, C.P., Jones, H. E. (2014). The WHO health promoting school framework for improving the health and well-being of students and their academic achievement. Cochrane Database Syst, Rev. 4, CD008958.

Manning, M. L., \& Lucking, R. (1991). The what, why, and how of cooperative learning. The Clearing House. 64(3), 152-156.

Marlina, R. L. (2011). Analisis Manajemen Promosi Kesehatan Dalam Penerapan Perilaku Hidup Bersih dan Sehat (PHBS) Tatanan Rumah Tangga di Kota Padang Tahun 2011. Padang: Universitas Andalas.

Maryunani, A. (2013). Perilaku Hidup Bersih dan Sehat. Jakarta: Trans Info Media.

McClure, M., Tarr, P., Thompson, C. M., \& Eckhoff, A. (2017). Defining quality in visual art education for young children: Building on the position statement of the early childhood art educators. Arts Education Policy Review, 118(3), 154-163. https://doi.org/10.1080/10632913.2016.1245167

Mcisaac, J. D., Sim, S. M., Penney, T. L., \& Kirk, S. F. L. (2012). School Health Promotion Policy in Nova Scotia: A Case Study. Revue PhénEPS / PHEnex Journal, 4(2).

McIsaac, J. L. D., Penney, T. L., Ata, N., Munro-Sigfridson, L., Cunningham, J., Veugelers, P. J., ... Kuhle, S. (2017). Evaluation of a health promoting schools program in a school board in Nova Scotia, Canada. Preventive Medicine Reports, 5, 279-284. https://doi.org/10.1016/j.pmedr.2017.01.008

Midcentraldhb. (2014). Health and Safety Guidelines for Early Childhood Education Services. https://doi.org/2014

Mikkonen, J., Raphael, D. (2010). Social Determinants of Health: The Canadian Facts. University School of Health Policy and Management Toronto.

Proverawati, A. (2012). Perilaku Hidup Bersih dan Sehat. Yogyakarta: Nuha Medika.

Reed, K.E., Warburton, D.E., Macdonald, H.M., Naylor, P.J., McKay, H. A. (2008). Action Schools! BC: a school-based physical activity intervention designed to decrease cardiovascular disease risk factors in children. Prev. Med, 46, 525-531.

Samdal, O., Rowling, L. (2011). Theoretical and empirical base for implementation components 
of health-promoting schools. Health Educ., 111, 367-390.

Syukriyah, E. (2011). Gambaran Pengetahuan, Sikap dan Tindakan Murid SD Tentang PHBS di SDN 06 Lubuk LayangPadang. Padang: Poletkkes Kemenkes Padang.

Veugelers, P. J., \& Schwartz, M. E. (2010). Comprehensive school health in Canada. Canadian Journal of Public Health = Revue Canadienne de Sante Publique, 101 Suppl(August), S58. https://doi.org/10.17269/cjph.101.1907

WHO. (2016). What is a health promoting school?

WIjayanti, N. A. (2017). Implementation of Role Playing Method in the Hygiene Hadith Learning Toward Early CHildrens Healthy Behavior of Group B in Dabin Aggrek Gunungpati Semarang. Early Childhood Education Papers (Belia), 6(2). 